\title{
A Study on Employee Job Satisfaction during COVID-19 Pandemic Era
}

\author{
Daggumalli. Deena Shakeena Kennedy \\ Rishi UBR PG College for Women, Hyderabad \\ Submitted to the Rishi Online National Conference
}

\begin{abstract}
This study is carried out with a primary objective to study employee job satisfaction during the covid 19 pandemic era. As the concept of job satisfaction is vital for the success of any organization because it can help to motivate employees to achieve higher productivity and to understand the needs, feelings, tastes and preferences of the employees. It also helps the organization as a whole to understand the dynamics of managing the employees in a productive way. With this overpowering pandemic taking control of every one's life, its new to every sector in the society and it's not possible from not being affected by it.

For employees where job satisfaction is mainly affected by workplace culture, climate etc and with this covid 19 pandemic changing the entire work environment, now job satisfaction is something that is affected based on different standards. The world is different today than it was a year ago. With COVID-19 being crawled across our communities for almost a couple of years we are still experiencing the disorder in our homes and workplaces. As the virus began its play, many organizations were forced to make drastic changes to the workplace due to global pandemic, and as a result, added to many disruptive employee experiences. For almost all the organizations remote work is being new normal. To maintain workplace culture while making this shift and to discover how to engage employees by recognizing the challenges that come with managing remote employees.
\end{abstract}

The main aim of the study is to determine job satisfaction as it helps to conclude various parameters to understand employee's perception towards the job.

\section{Keywords: Employee Satisfaction, Pandemic, COVID-19, Workplace Environment, Remote Work}

\section{Introduction}

Job satisfaction is such an important factor, which always draws the attention of managers of all the organizations and many researchers. There are many studies that have been conducted to find out the factors by which job satisfaction factors are determined and the way by which productivity is influenced in the organizations.

\section{Definition}

According to DURBINS, Job satisfaction is the amount of pleasure or contentment that is associated with a job. If you dislike your job intensely, you will experience job dissatisfaction.

Job satisfaction refers to satisfaction on the job, which tends to act as a motivator in work. Due to the dynamic nature of the environment, organizations are facing several challenges in the modern era. One of the biggest challenges is to satisfy the employees of their organizations in order to cope up with 
continuously evolving environment and to be undisturbed in the competition. To satisfy the needs of its employees by providing good working conditions which helps in increase of efficiency, effectiveness is very important for any organization, which many businesses fail to understand and thus face many problems during their work. In today's competitive market, it is essential for the employees to put lot of dedication and hard work.

In the times of COVID-19, organizations all over the world have closed their offices and shifted to their work to their homes to stop the further spreading of the novel virus, resulting in increase of stress and anxiety among employees, which affected their satisfaction with life. Thus, the present study analyses the effect of COVID-19 on employees. The impact of such distress on job performance of employees which reduced life satisfaction is analysed.

Despite all these factors that ruled the measurement of job satisfaction before the pandemic, the covid 19 entrance changed the whole scenario where all the previous factors were ruled out because work environment is no longer the actual one but the remote environment.

\section{Objectives}

- To study the level of Job Satisfaction among the employees with the option of work from home.

- To study the various areas of improvement for job satisfaction.

- To present some suggestions to the management on how to improve the job satisfaction levels of employees.

\section{Review of Literature}

1) Alam Sageer, Dr. Sameena Rafat, Ms. Puja Agarwal (Sep-Oct. 2012) Employee satisfaction is the terminology used to describe whether employees are happy, contended and fulfilling their desires and needs at work. Many measures support that employee satisfaction is a factor in employee motivation, employee goal achievement and positive employee morale in the workplace. Basically, Employee satisfaction is a measure of how happy workers are with their job and working environment. In this paper various variables responsible for employee satisfaction have been discussed such as Organization development factors, Job security factors, Work task factors, Policies of compensation and benefit factor and opportunities which give satisfaction to employees such as Promotion and career development also has been described. This paper also deals with the various ways by which one can improve employee satisfaction.

2) Dr. P. K. Mishra (Sep. - Oct. 2013) Job satisfaction is one of the most crucial but controversial issues in industrial Psychology and behavioural management in organizations. It ultimately decides the extent of employee motivation through the development of organizational climate or environment satisfaction as a specific subset of attitudes held by organizational members. It is the attitude one has towards his or her job. Stated another way, it is one's effective response to the job. Job satisfaction in a narrow sense means attitudes related to the job. It is concerned with such specific factors as wages, supervision, steadiness of employment, conditions of work, social relation of the job, prompt settlement of grievances, fair treatment of the employer and other similar items. Job satisfaction is related to different Socio-economic and personal factors, such as: Age, Sex, Incentives, Working Environment, Education, duration of work etc. The present paper will highlight different factors affecting job satisfaction in a pharmaceutical company in Sikkim, India. 
3) Ian A. lane, Michelle G. Mullen, and Amanda Costa (2020)Due to the COVID-19 Pandemic many workers are shifting from coming into their workplace to working from home. This may be a new challenge for many workers. Successfully working from home can present unique challenges, from how to focus with at-home distractions, to trying to be productive, trying to communicate well with team members from afar, and childcare. Here at the Transitions to Adulthood Centre for Research, many of our faculty and staff have years of experience mastering the art of remote work and have put together a list of their top 5 tips and tricks to navigating this strange new world.

4) Helena Bulinska-Stangrecka and Anna Bagienska (2021) The COVID-19 pandemic is affecting the mental health of employees. Deterioration of the well-being of workers is also caused by changes in the working environment. Remote working can affect both social interactions and job satisfaction. The purpose of the study is to examine what factors influence job satisfaction in the context of remote work caused by a pandemic. The study analyses whether employee relations and interpersonal trust are related to the level of perceived job satisfaction. The investigation started with a literature review and then research hypotheses were formulated. Based on an empirical study, carried out on a sample of 220 IT employees during the pandemic, an analysis of the mediating role of trust in links between employee relations and perceived job satisfaction was conducted. The current study found that positive employee relations contribute to the level of job satisfaction. Additionally, trust is an important factor that mediates these relationships. Based on the results of the research, it was possible to describe the mechanism of shaping a supportive work environment during a pandemic.

5) Peter karacson (2021) The COVID-19 pandemic, which became a global crisis in 2020, has radically transformed people's normal lives in a matter of weeks. In addition to the health consequences, the virus has had a significant impact on the society and the economy, including the labour market. The present study aims to assess how traditional working has been transformed into teleworking in Slovakia. The study examines whether Slovakian workers are satisfied with teleworking. The questionnaire survey was conducted in December 2020 during the second wave of the coronavirus in Slovakia. Based on the obtained results, a significant relationship between teleworking satisfaction and salary satisfaction, supervisory support, and job autonomy was found. Based on the obtained results, teleworking introduced due to the coronavirus had a clear positive effect on job satisfaction of the examined Slovakian employees. As a result of teleworking, the relationship between manager and subordinate has improved, and work-life balance has also developed favourably.

\section{Research Methodology}

\section{Sample Design}

Sampling Techniques: For present study, a convenient sampling technique was used.

Sample Size: The study was conducted by taking a sample size of 120 employees.

Sample Unit: The sample unit was employees of IT companies.

Sample instrument: A structured questionnaire was used for collecting primary data. The questionnaire consists of two parts. Part one focused on demographic factors like age, income, educational qualification etc., of employees. Second part focused on opinions of the employee's job satisfaction.

Type of Questionnaire: The data was collected with the help of a structured questionnaire consisting of 11 questions. They will be closed ended questions. The time required for filling the questionnaire is approximately 5 minutes. 
Type of Questions: For the present study options like 5-point scale are used with Highly satisfied, Satisfied, Neutral, Dissatisfied, highly dissatisfied and close ended questions will be used to measure Employee Job satisfaction during covid 19 pandemic era.

\section{Sources of Data}

Primary Data, Secondary Data

\section{Data Analysis Tools \& Techniques}

The present study used percentage analysis and weighted average to find Employee Job satisfaction

Percentage analysis $=\frac{\text { No. of Respondents }(\text { For Particular Question })}{\text { Total No.of Respondent }} \times 100$

Weighted Average $=\frac{\text { Sum of the Number }}{\text { Total No.of Respondents }} \times$ Weighting Factors

\section{Limitations}

1. Due to pandemic there's a restriction to enter any company so 120 responses were only collected

2. As there's no face-to-face interaction during these times data was only collected through google forms

3. There are some constraints in terms of narrowing the time horizon of the study

4. Another limitation concerns the geographical narrowing of the research that has been carried out

5. An additional limitation is also the restriction of the research to the IT companies

\section{Data Analysis}

\section{Demographic Factors}

Majority of the respondents are male (97\%), with PG educational qualification (59\%), with an age group of 40 to 50 years, $(60 \%), 5$ to 10 years of experience $(72 \%)$.

\section{Like About the Job}

Weighted average is 3.925 and the value of weighted average is between $3 \& 4$. So, most of the respondents said that, they are satisfied with their job.

\section{Satisfaction About Job Security}

Weighted average is 4.166 and the value of weighted average is 4 . So, most of the respondents said that, they are satisfied with the job security in the company.

\section{Methods of Promotion}

Weighted average is 4.15 and the value of weighted average is 4 . So, most of the respondents said that, they are satisfied with the methods of promotion followed by the company.

\section{Frequency of Feedback}

Weighted average is 3.658 and the value of weighted average is between $3 \& 4$. So, most of the respondents said that, they are satisfied with the frequency of feedback on company's decisions.

\section{Equal Distribution of Work Load}

Weighted average is 3.65 and the value of weighted average is between $3 \& 4$. So, most of the respondents 
said that, they are satisfied with the equal distribution of workload.

\section{Employer Assistance}

Weighted average is 3.858 and the value of weighted average is between $3 \& 4$. So, most of the respondents said that, they are satisfied with the superiors assistance in their work.

\section{Job Satisfaction Factors}

$25 \%$ of the respondents said that, respect at job is the satisfying factor, $17 \%$ said recognition, $13 \%$ both growth in career and good work place are the factors, $11 \%$ said value your feedback, $10 \%$ all kinds of benefits, $6 \%$ said compensation and $5 \%$ of the respondents said, all the factors like respect, benefits, feedback etc., will give satisfaction. All the above are the factors that affect job satisfaction.

\section{Satisfaction of Work Space}

From the above calculation it is clear that the weighted average is 4.025 and the value of weighted average is 4 . So, most of the respondents said that, they are satisfied with the workspace where they can work at home.

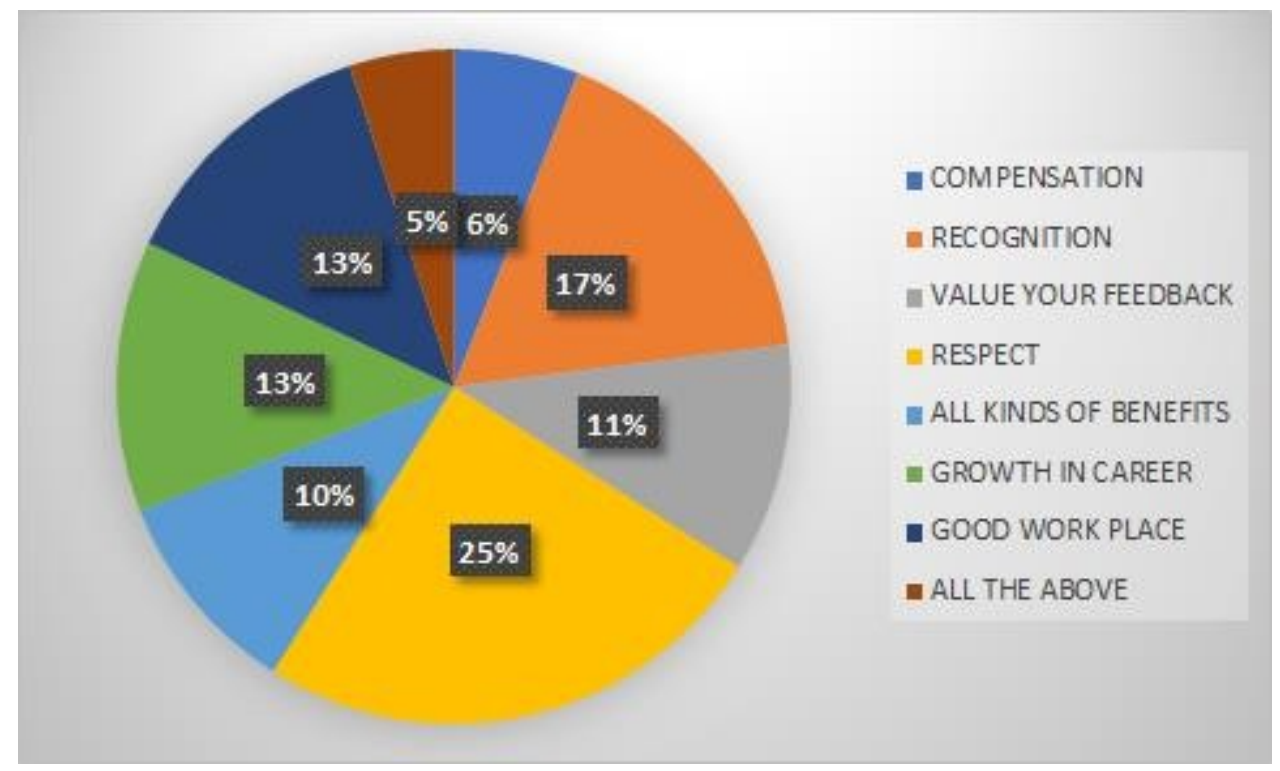

\section{Stable Internet Connection}

Weighted average is 3.975 and the value of weighted average is between $3 \& 4$. So, most of the respondents said that, they are satisfied the stability of internet connections to work at home.

\section{Equal Distribution of Work Load}

Weighted average is 3.65 and the value of weighted average is between $3 \& 4$. So, most of the respondents said that, they are satisfied with the equal distribution of work load.

\section{Information to Make Correct Decision}

Weighted average is 4.041 and the value of weighted average is 4 . So, most of the respondents said that, they are satisfied with having health relationship with their co-workers.

\section{Findings}

1. Majority of the respondents are male (97\%), with PG as educational qualifications(59\%), with an age group of 40 to 50 years $(60 \%)$, and 5 to 10 years of experience $(72 \%)$ and majority are from technical department (42\%). 
2. Most of the respondents said that, they are satisfied (3.925) with their job.

3. Most of the respondents said that, they are satisfied (4.166) with the job security in the company.

4. Most of the respondents said that, they are satisfied (4.15) with the methods of promotion followed by the company.

5. Most of the respondents said that, they are satisfied (3.658) with frequency of feedback on company's decision.

6. Most of the respondents said that, they are satisfied (3.65) with the equal distribution of workload.

7. Most of the respondents said that, they are satisfied (3.858) with the support of employer in their work.

8. $25 \%$ of the respondents said that, respect is the main factor that gives job satisfaction to the employees.

9. Most of the respondents said that, they are satisfied (4.025) with the dedicated work space they have at home to work.

10. Most of the respondents said that, they are satisfied (3.975) with stable internet connection to work at home.

11. Most of the respondents said that, they are satisfied (4.366) with the balancing of their work life and family life.

12. Most of the respondents said that, they are satisfied (4.041) with the appropriate amount of information to make the correct decision about the work

\section{Conclusion}

In the light of COVID-19 pandemic, research on the mental health of employees has become increasingly more. Due to the negative effects, the pandemic is leading the whole world to, it has become more important to know and analyse the impact of the effects in all the corners. Mainly when it comes to organizations where all of their employees working from home is the new normal, so they'll have to consider to talk about the advantages and the adversaries of this new normal. There are numerous new fears that are ruling the employees and the top ones are illness and social isolation, as maintaining good relations with co-workers being in there very own homes is difficult. Problems like maintaining working environment, stability in the internet, prolonged working hours are driving negative energy to the employees. Management should consider all these adversaries in calculating job satisfaction, because the parameters of calculating job satisfaction will never be the same with the entrance of the COVID-19 pandemic. Many psychological factors being in home $24 / 7$ is pulling down the job performance of the employees. As every home is having their own covid stories management should be good enough to consider them and help them to come out of their battles.

\section{References}

1. Dr. P. K. Mishra. IOSR Journal of Business and Management (IOSR-JBM) ISSN:2278487X.Volume5,Issue1(Sep-Oct.2012),PP32-39

2. AlamSageer, Dr. Sameena Rafat, Ms. Puja Agarwal: Identification of VariablesAffecting Employee Satisfaction and Their Impact on the Organization "IOSR Journalof Humanities and Social Science(IOSR-JHSS) Volume 14, Issue 5 (Sep. - Oct.2013),PP45-54e-ISSN:2279-0837,p-ISSN:22790845 .

3. Ian A. lane, Michelle G. Mullen, and Amanda Costa (2020) Working from Home During the COVID19 Pandemic: Tips and Strategies to Maintain Productivity \& Connectedness. Document Type Transitions ACR ,2020-04-02 DOI10.7191/pib.1145

4. Shilpi Arora and Dr. Sandeep Vyas (2020) Job satisfaction at the time of COVID-19: An investigation of information technology sector in India. Volume IX, Issue IX, SEPTEMBER/2020, ISSN NO: 23473150, PageNo: 251, ISSN NO: 2347-3150 
5. Peter Karacson (2021) Impact of teleworking on job satisfaction among Slovakian employees in the era of COVID-19. Volume 19 2021, Issue \#3, pp. 1-9 Published online 2021:

http://dx.doi.org/10.21511/ppm.19(3).2021.01

6. https://www.businessperspectives.org/index.php/journals/problems-and-perspectives-in-management/ issue-386/impact-of-teleworking-on-job-satisfaction-among-slovakian-employees-in-the-era-of-covid$\underline{19}$

7. https://www.sciencedirect.com/science/article/pii/S2212567115005249

8. https://www.ncbi.nlm.nih.gov/pmc/articles/PMC7920272/

9. https://www.sciencedirect.com/science/article/pii/S2093791121000603

10. https://www.tandfonline.com/doi/full/10.1080/25741292.2020.1863560

\section{Annexure}

Your age (in years):

(a) 20 to 30 (b) 31 to 40 (c) 41 to 50 (d) 51 and above

Gender:

(a) Male (b) Female (c) Other

Educational Qualifications:

(a) Diploma (b) Inter (c) Degree (d) PG (e) Other

Experience (in years):
(a) Less than 5 years $($ b)
(b) 5-10 years $(c)$
(c) 11-20 years $(\mathrm{d})$
(d) More than 20 years

1. How do you like your job?

(a) Highly satisfied (b) Satisfied (c) Neutral (d) Dissatisfied (e) Highly dissatisfied

2. How do you feel about job security in your company?

(a) Highly satisfied (b) Satisfied (c) Neutral (d) Dissatisfied (e) Highly dissatisfied

3. Are you satisfied with the methods of promotions your company is following?

(a) Highly satisfied (b) Satisfied (c) Neutral (d) Dissatisfied (e) Highly dissatisfied

4. Have you been frequently asked to provide feedback on a company's decision?

(a) Highly satisfied (b) Satisfied (c) Neutral (d) Dissatisfied (e) Highly dissatisfied

5. Do you feel that the workload is equally distributed in your department?

(a) Highly satisfied (b) Satisfied (c) Neutral (d) Dissatisfied (e) Highly dissatisfied

6. Do you have support from your employer to work from home?

(a) Highly satisfied (b) Satisfied (c) Neutral (d) Dissatisfied (e) Highly dissatisfied

7. What do you think are the factors that effects job satisfaction?

(a) Compensation (b) Recognition (c) Value your feedback (d) Respect (e) All kinds of benefits (f) Growth in career (g) Good workplace culture (h) All the above 
8. Do you have a dedicated workspace where you can work at home?

(a) Highly satisfied (b) Satisfied (c) Neutral (d) Dissatisfied (e) Highly dissatisfied

9. Do you have a stable internet connection to work at home?

(a) Highly satisfied (b) Satisfied (c) Neutral (d) Dissatisfied (e) Highly dissatisfied

10. Do you feel you have good work life balance working in your company?

(a) Highly satisfied (b) Satisfied (c) Neutral (d) Dissatisfied (e) Highly dissatisfied

11. Do you have the appropriate amount of information to make the correct decision about your work?

(a) Highly satisfied (b) Satisfied (c) Neutral (d) Dissatisfied (e) Highly dissatisfied 